\title{
Tumor Enhancement on Dynamic CT: A Predictive Factor for Recurrence After Nephrectomy in Localized T1 Clear Cell Renal Cell Carcinoma
}

\author{
JUNKI MAEHARA ${ }^{1}$, AKIHIRO NISHIE ${ }^{1}$, YOSHIKI ASAYAMA ${ }^{1}$, KOUSEI ISHIGAMI ${ }^{1}$, \\ YASUHIRO USHIJIMA ${ }^{1}$, YUKIHISA TAKAYAMA $^{1}$, DAISUKE OKAMOTO ${ }^{1}$, \\ NOBUHIRO FUJITA ${ }^{1}$, MASAAKI SUGIMOTO ${ }^{2}$, JUNICHI INOKUCHI ${ }^{3}$ and HIROSHI HONDA ${ }^{1}$ \\ Departments of ${ }^{1}$ Clinical Radiology, ${ }^{2}$ Anatomic Pathology and ${ }^{3}$ Urology, \\ Graduate School of Medical Sciences, Kyushu University, Fukuoka, Japan
}

\begin{abstract}
Aim: To investigate whether radiological parameters obtained on dynamic computed tomography (CT), especially those related to tumor enhancement, are predictive factors for recurrence after nephrectomy in localized stage Tl clear cell renal cell carcinoma (ccRCC). Materials and Methods: We retrospectively studied 88 patients with localized stage TI ccRCC who underwent dynamic CT preoperatively. Seven patients had recurrent disease after surgery. Tumor attenuations were measured by placing a region of interest in the solid region. $T A_{\text {pre }}$ and $T A_{\text {neph }}$ were defined as the tumor attenuation values of the pre-contrast and nephrographic phase, respectively. The correlations between disease-free survival and clinicopathological factors, including the radiological parameter $T A_{\text {neph }}-T A_{\text {pre }}\left(\Delta T A_{\text {neph }}\right)$, were analyzed by Cox proportional hazards model or Kaplan-Meier method with the log-rank test. Results: Only $\triangle T A_{\text {neph }}$ was significantly and positively correlated with disease-free survival $(p<0.05)$. Tumor size also tended to be negatively correlated with disease-free survival $(p<0.1)$. The 5- and 10-year disease-free survival rates of the group with high $\Delta T A_{\text {neph }}(\geq 86 \mathrm{HU})$ were $97.4 \%$ and $97.4 \%$, while those of the group with low $\triangle T A_{\text {neph }}(<86 \mathrm{HU})$ were $89.6 \%$ and $71.6 \%$, respectively. Conclusion: Tumor enhancement in the nephrographic phase of CT was a predictive factor for recurrence after nephrectomy in patients with localized stage T1 ccRCC.
\end{abstract}

Renal cell carcinoma (RCC) is the most common type of cancer observed in the adult kidney (1). Although there are

Correspondence to: Akihiro Nishie, Department of Clinical Radiology, Graduate School of Medical Sciences, Kyushu University, 3-1-1 Maidashi, Higashi-ku, Fukuoka 812-8582, Japan. E-mail: anishie@radiol.med.kyushu-u.ac.jp

Key Words: RCC, clear cell, CT, recurrence, tumor enhancement several subtypes of RCC, clear cell renal cell carcinoma (ccRCC) accounts for $70 \%$ of all cases (2). Typically, ccRCCs enhance avidly and heterogeneously on dynamic computed tomography (CT) $(3,4)$. Nonetheless, some ccRCCs enhance poorly and homogeneously, with their imaging features overlapping features that are more typical of the non-clear-cell variants, such as papillary or chromophobe RCCs (5). High microvascular density (MVD) has been reported to be a predictive factor of metastasis, recurrence and prognosis in $\operatorname{ccRCC}(2,6)$, but other reports have suggested that a low MVD predicts distant metastasis and poor prognosis $(7,8)$. Because the relationship between tumor vascularity and prognosis in ccRCC is controversial, further validation is required. High-grade ccRCC frequently contains foci of fibrosis (7). In addition, Pichler et al. reported that the presence of histological tumor necrosis represents an independent predictor with respect to metastasis-free and overall survival in patients with clear cell and papillary RCC (9). Therefore, we hypothesized that a radiological parameter reflecting such histological findings could be a predictive factor obtained in a noninvasive fashion.

One of the strongest validated prognostic factors in RCC is tumor stage (anatomical extent of disease) (10). Nevertheless, stage T1 ccRCC can also recur or metastasize after surgery (11). It would, therefore, be clinically helpful if we could recognize patients with stage T1 ccRCC for whom particular care should be taken. Tumor size and Furman grade have been reported to be prognostic factors at stage pT1 $\operatorname{ccRCC}(12,13)$.

To the best of our knowledge, few radiological parameters have been reported as prognostic factors of ccRCC in contrast to biological and pathological markers (14-17). Tumor enhancement of ccRCC on dynamic CT is diverse. This enhancement is supposed to reflect tumor vascularity and the presence of fibrous stroma, necrosis and hemorrhage, 
etc. Furthermore, differences in tumor volume may influence dynamics of contrast agent within a tumor. The volume of a contrast agent used in daily practice may be insufficient for evaluating tumor enhancement or vascularity of a large tumor even if the same scan timing is used. This potentially confounding factor can be excluded by focusing only on small tumors.

The purpose of this study was to investigate whether radiological parameters obtained on dynamic CT, especially those related to tumor enhancement, are predictive of recurrence after nephrectomy in localized stage T1 ccRCC.

\section{Materials and Methods}

Patients. We conducted a retrospective study based on medical data archived at our hospital. Institutional Review Board approval (no. 28-121) was obtained, and the requirements for informed consent were waived. We enrolled 189 patients who had been diagnosed with ccRCC after surgery between January 2001 and May 2013. All patients had undergone a preoperative dynamic CT examination and radical or partial nephrectomy for renal tumors. A preoperative dynamic CT examination was performed within 3 months before surgery. Nine patients were excluded due to the presence of lymph node or distant metastasis. In seven patients, the tumor was pathologically diagnosed as more advanced than stage T2. Eightyfive patients who were not followed-up at our hospital for more than 2 years were also excluded. The final study group thus consisted of 88 patients with localized ccRCC (TNM staging: T1N0M0): 64 T1a and $24 \mathrm{~T} 1 \mathrm{~b}$. The details of the patient profiles and pathological findings are summarized in Table I. Each patient had only one RCC. The surgical methods performed included total nephrectomy in 45 patients and partial nephrectomy in 43 patients. After surgery, chestabdomen-pelvis CT examinations were performed every 3, 6, or 12 months, for the purpose of surveillance for recurrence and metastasis. A few patients underwent dynamic CT examinations to rule out surgical complications while they were in the hospital. The frequency of complications in our population was low in comparison with the previous report (18). Disease-free survival was defined as the time from surgery to the first documentation of recurrence or distant metastasis on CT reports. Recurrence or distant metastasis was defined as a new solid lesion showing interval increase in size on a series of follow-up CT.

Dynamic CT. Preoperative CT was performed with a 4- or 64multidetector row CT (MDCT) scanner (Aquilion, Toshiba Medical, Tokyo, Japan). First, pre-contrast CT images were scanned. A total of $100 \mathrm{ml}$ of a nonionic iodinated contrast agent (iopamidol: Iopamiron 370; Bayer, Osaka, Japan) was injected through the antecubital vein for $40 \mathrm{~s}$ at an injection rate of $2.5 \mathrm{ml} / \mathrm{s}$ using a power injector. The time delays for scanning for corticomedullary-, nephrographic- and excretory-phase images were 45 (4-MDCT) or 48 (64-MDCT) s, $90 \mathrm{~s}$, and $240 \mathrm{~s}$, respectively. The scanning parameters with 4-MDCT were $120 \mathrm{kVp}, 300 \mathrm{mAs}, 3-\mathrm{mm}$ collimation reconstructed to a slice thickness of $5 \mathrm{~mm}$, and a pitch of 3, while the scanning parameters with 64 -MDCT were $120 \mathrm{kVp}$, automatically set $\mathrm{mAs}, 0.5-\mathrm{mm}$ collimation reconstructed to a slice thickness of $5 \mathrm{~mm}$, and a pitch of 53. The images were obtained in the craniocaudal direction.
Table I. Patients profile and pathological findings of localized stage T1 clear cell renal cell carcinoma*.

\begin{tabular}{lc}
\hline Variable & Value \\
\hline Age (years) & \\
Range & $26-82$ \\
Median & 60.4 \\
Gender, $\mathrm{n}$ & \\
Male & 63 \\
Female & 25 \\
Tumor side, $\mathrm{n}$ & \\
Left & 40 \\
Right & 48 \\
Tumor size (cm) & $1.0-6.2$ \\
Range & 3.1 \\
Median & \\
Growth/invasion pattern & 87 \\
Expansive & 1 \\
Intermediate & \\
Furman grade, $\mathrm{n}$ & 7 \\
G1 & 77 \\
G2 & 4 \\
G3 or more & \\
Venous invasion, $\mathrm{n}$ & 53 \\
Positive & \\
Negative & \\
\hline
\end{tabular}

*Each patient had a single tumor.

Image analysis. All CT images were independently reviewed by two radiologists (J.M. and A.N., with 3 and 22 years of experience, respectively). After the entire slices describing each tumor were observed, one slice including as large an area of the solid region of the tumor as possible was visually selected. A round or oval region of interest (ROI) was placed on the tumor to measure tumor attenuation in each dynamic phase (pre-contrast, corticomedullary, nephrographic and excretory phases). The ROI was carefully positioned to cover as much of the solid region of the tumor as possible, while avoiding any region of necrosis or hemorrhage. An ROI of the same size was placed at the same position on the image of each phase by copy and paste method.

$\mathrm{TA}_{\mathrm{pre}}, \mathrm{TA}_{\mathrm{cor}}, \mathrm{TA}_{\mathrm{neph}}$ and $\mathrm{TA}_{\mathrm{ex}}$ were defined as tumor attenuation values of pre-contrast, corticomedullary, nephrographic and excretory phases, respectively. By referring to these four values, a total of five radiological parameters were evaluated:i) $\mathrm{TA}_{\text {pre }}$ itself, which may reflect cytoplasmic fat in $\operatorname{ccRCC}(19)$; ii) $\mathrm{TA}_{\text {cor }}-\mathrm{TA}_{\text {pre }}$ and iii) $\mathrm{TA}_{\text {neph }}-\mathrm{TA}_{\text {pre }}\left(\Delta \mathrm{TA}_{\text {neph }}\right)$, which may represent tumor enhancement; iv) absolute percentage washout using the corticomedullary phase $(\mathrm{APW}$ cor $)=\left(\mathrm{TA}_{\text {cor }}-\mathrm{TA}_{\mathrm{ex}}\right) /\left(\mathrm{TA}_{\text {cor }}-\mathrm{TA}_{\mathrm{pre}}\right)$ $\times 100$; and $v$ ) absolute percentage washout using the nephrographic phase $\left(\mathrm{APW}_{\text {neph }}\right)=\left(\mathrm{TA}_{\text {neph }}-\mathrm{TA}_{\mathrm{ex}}\right) /\left(\Delta \mathrm{TA}_{\text {neph }}\right) \times 100 . \mathrm{APW}_{\text {cor }}$ and $\mathrm{APW}_{\text {neph }}$ may be affected by the amount of fibrosis in the tumor (20). These five radiological parameters were measured by the two radiologists. The average values were applied to the evaluation.

Pathological diagnosis. The resected specimens were sliced by making a series of axial incisions approximately $5 \mathrm{~mm}$ apart according to CT sections. In all cases, the entire area of the cut surface containing the greatest tumor dimensions was submitted for 
Table II. Five radiological parameters in patients according to recurrence of localized stage T1 clear cell renal cell carcinoma. Data are the mean $\pm S D$ (range).

\begin{tabular}{lcc}
\hline Parameter & Recurrence $(\mathrm{n}=7)$ & No-recurrence $(\mathrm{n}=81)$ \\
\hline $\mathrm{TA}_{\text {pre }}(\mathrm{HU})$ & $35.6 \pm 8.7(18.1-47.7)$ & $32.0 \pm 7.0(18.8-47.2)$ \\
$\mathrm{TA}_{\text {cor }}-\mathrm{TA}_{\text {pre }}(\mathrm{HU})$ & $116.5 \pm 39.9(71.6-199.9)$ & $146.2 \pm 50.4(28.7-263.9)$ \\
$\Delta \mathrm{TA}_{\text {neph }}(\mathrm{HU})$ & $69.2 \pm 18.2(36.9-96.4)$ & $94.3 \pm 32.2(33.5-214.2)^{*}$ \\
$\mathrm{APW}_{\text {cor }}(\%)$ & $56.0 \pm 14.6(22.7-69.9)$ & $52.3 \pm 21.0(-84.9-75.5)$ \\
$\mathrm{APW}_{\text {neph }}(\%)$ & $30.6 \pm 6.6(18.4-39.7)$ & $32.1 \pm 9.7(2.4-53.3)$ \\
\hline
\end{tabular}

$\mathrm{TA}_{\text {pre }}, \mathrm{TA}_{\text {cor }}, \mathrm{TA}_{\text {neph }}, \mathrm{TA}_{\mathrm{ex}}$ : Pre-contrast, corticomedullary, nephrographic and excretory phase tumor attenuation, respectively; $\Delta \mathrm{TA}_{\text {neph }}=\mathrm{TA}_{\text {neph }}-$ $\mathrm{TA}_{\text {pre }}$; APWcor: absolute percentage corticomedullary phase washout $\left[\left(\mathrm{TA}_{\text {cor }}-\mathrm{TA}_{\mathrm{ex}}\right) /\left(\mathrm{TA}_{\text {cor }}-\mathrm{TA}_{\text {pre }}\right) \times 100\right] ; \mathrm{APW}_{\text {neph }}$ : absolute percentage nephrographic phase washout $\left[\left(\mathrm{TA}_{\text {neph }}-\mathrm{TA}_{\mathrm{ex}}\right) /\left(\Delta \mathrm{TA}_{\text {neph }} \times 100\right]\right.$. *Means significantly different at $p=0.048$. There was no significant difference in the other radiological parameters between the two groups.

pathological examination. These specimens were fixed in $10 \%$ formalin, cut into $4-\mu \mathrm{m}$ sections, and stained with hematoxylin-eosin. Additional samples were also taken from other parts to evaluate the pathological findings, including the tumor size, growth/invasion pattern, Fuhrman grade, histological subtype, and venous invasion. We employed the worst nuclear grade as the Fuhrman grade here.

Statistical analysis. The above radiological parameters were compared between groups with and without recurrence using Student's $t$-test. The clinicopathological factors evaluated were patient age and gender, surgical method, tumor side, tumor size, Fuhrman grade, growth/invasion pattern, venous invasion, and the above radiological parameters. We analyzed the correlations between these factors and ccRCC disease-free survival using the Cox proportional hazards model or the Kaplan-Meier method with log-rank test (univariate analysis). The Cox proportional hazards model was applied for continuous variables, while the Kaplan-Meier analysis with the log-rank test was used for independent variables. When there was a significant correlation between a continuous variable and disease-free survival using the Cox proportional hazard model, Kaplan-Meier analysis with log-rank test was added. The threshold for division into two groups was obtained based on the median value. Pearson's correlation coefficient was also calculated to assess the inter-reader variability in measurement of $\Delta \mathrm{TA}_{\text {neph. }} p$-Values of less than 0.05 were considered to indicate significance.

\section{Results}

Seven out of the 88 patients $(8.0 \%)$ had recurrent disease 0.3 to 89.3 months after the day of surgery, and the remaining 81 patients showed no recurrence at 24.0 to 163.6 months after surgery. The median postoperative follow-up duration of the whole patient cohort was 66.8 months. Recurrence was clinically diagnosed on CT. The sites of recurrence the seven patients were bone in three, lung in three, and local, pancreas, contralateral kidney and lymph nodes in one each. Three patients had recurrent lesions in two organs.
Table III. Univariate analyses of clinicopathological factors and disease-free survival in patients with localized stage T1 clear cell renal cell carcinoma.

\begin{tabular}{|c|c|c|c|}
\hline & Hazard ratio & $95 \% \mathrm{CI}$ & $p$-Value \\
\hline \multicolumn{4}{|c|}{ Cox proportional hazards model } \\
\hline Age & 1.00 & $0.942-1.062$ & 0.99 \\
\hline Tumor size & 1.63 & $0.972-2.742$ & 0.063 \\
\hline Fuhrman grade & 1.84 & $0.157-19.45$ & 0.62 \\
\hline $\mathrm{TA}_{\text {pre }}(\mathrm{HU})$ & 1.06 & $0.956-1.181$ & 0.26 \\
\hline $\mathrm{TA}_{\text {cor }}-\mathrm{TA}_{\text {pre }}(\mathrm{HU})$ & 0.99 & $0.976-1.007$ & 0.27 \\
\hline$\Delta \mathrm{TA}_{\mathrm{neph}}(\mathrm{HU})$ & 0.97 & $0.935-0.997$ & 0.034 \\
\hline $\mathrm{APW}_{\text {cor }}(\%)$ & 11.2 & $0.031-4044$ & 0.42 \\
\hline $\mathrm{APW}_{\text {neph }}(\%)$ & 0.98 & $0.001-170.9$ & 0.47 \\
\hline
\end{tabular}

Kaplan-Meier analysis with log-rank test

\begin{tabular}{llll}
\hline Gender & - & - & 0.14 \\
Surgical method & - & - & 0.16 \\
Tumor side & - & - & 0.15 \\
Venous invasion & - & - & 0.48 \\
\hline
\end{tabular}

$\mathrm{TA}_{\text {pre }}, \mathrm{TA}_{\text {cor }}, \mathrm{TA}_{\text {neph }}, \mathrm{TA}_{\mathrm{ex}}$ : Pre-contrast, corticomedullary, nephrographic and excretory phase tumor attenuation, respectively; $\Delta \mathrm{TA}_{\text {neph }}=\mathrm{TA}_{\text {neph }}-$ $\mathrm{TA}_{\text {pre}} ; \mathrm{APW}_{\text {cor }}$ : absolute percentage corticomedullary phase washout $\left[\left(\mathrm{TA}_{\text {cor }}-\mathrm{TA}_{\mathrm{ex}}\right) /\left(\mathrm{TA}_{\text {cor }}-\mathrm{TA}_{\text {pre }}\right) \times 100\right] ; \mathrm{APW}_{\text {neph }}$ : absolute percentage nephrographic phase washout $\left[\left(\mathrm{TA}_{\text {neph }}-\mathrm{TA}_{\mathrm{ex}}\right) /\left(\Delta \mathrm{TA}_{\text {neph }}\right) \times 100\right] ; 95 \%$ CI: $95 \%$ confidence interval.

Details of the five radiological parameters in patients according to recurrence are shown in Table II. The average $\Delta \mathrm{TA}_{\text {neph }}$ in group without recurrence was significantly higher than that in group with $(p=0.048)$. There was no significant difference in the other four radiological parameters between the two groups.

The results for the univariate analyses are summarized in Table III. Most tumors showed expansive growth; one tumor had an intermediate pattern and thus its growth/invasion could not be evaluated. As a result, only $\Delta \mathrm{TA}_{\text {neph }}$ was significantly and positively correlated with disease-free survival $(p<0.05)$. Tumor size also tended to be negatively correlated with disease-free survival $(p<0.1)$.

We generated and analyzed a disease-free survival curve according to $\Delta \mathrm{TA}_{\text {neph }}$ (Figure 1). The median value of $\Delta \mathrm{TA}_{\text {neph }}$ in $88 \mathrm{ccRCCs}$ was $86 \mathrm{HU}$. Based on this value, all ccRCCs were divided into one of two groups: a high $\triangle \mathrm{TA}_{\text {neph }}$ group ( $\geq 86 \mathrm{HU})$ and a low $\Delta \mathrm{TA}_{\text {neph }}$ group $(<86 \mathrm{HU})$. The 5 -year disease-free survival rate of the high $\Delta \mathrm{TA}_{\text {neph }}$ group was $97.4 \%$, and that of the low $\Delta \mathrm{TA}_{\text {neph }}$ group was $89.6 \%$. The 10 -year disease-free survival rates were $97.4 \%$ and $71.6 \%$, respectively. The disease-free survival rate of the group with high $\Delta \mathrm{TA}_{\text {neph }}$ was significantly higher than that of those with a low $\Delta \mathrm{TA}_{\text {neph }}(p<0.05)$. For the other four parameters, no significant correlation with disease-free survival was obtained. 
The Pearson's correlation coefficient between $\Delta \mathrm{TA}_{\text {neph }}$ values measured by two radiologists was 0.90 , suggesting excellent inter-reader agreement.

Representative cases are shown in Figures 2 and 3.

\section{Discussion}

The radiological parameter $\Delta \mathrm{TA}_{\text {neph }}$ represents tumor enhancement in the nephrographic phase. In the present study this tumor enhancement was a predictive factor for recurrence after nephrectomy in localized stage T1 ccRCC. To the best of our knowledge, a predictive factor obtained by preoperative dynamic CT has rarely been reported (14). The parameter $\Delta \mathrm{TA}_{\text {neph }}$ may be clinically useful because it can be used in the selection of a therapeutic strategy and in the determination of an appropriate interval for follow-up imaging after surgery. It also can be obtained in a noninvasive fashion and without extra radiation exposure.

The ccRCCs demonstrating low tumor enhancement in the nephrographic phase showed a significantly higher incidence of recurrence. We consider that two factors, namely tumor vascularity and contrast agent dynamics in the stroma of the tumor, may be associated with tumor enhancement in the nephrographic phase. Another radiological parameter, $\mathrm{TA}_{\text {cor }}$ $-\mathrm{TA}_{\text {pre }}$, may represent tumor vascularity more directly. This parameter, however, was not associated with prognosis in the present study. There was no significant difference in $T A_{c o r}-$ $T A_{\text {pre }}$ between the groups according to recurrence. According to these results, the relevance of tumor vascularity to recurrence may be less considered. Neither APWcor nor APWneph was a predictive factor, although these parameters have been shown to account for contrast agent dynamics in the stroma (20). The amount of fibrosis in the tumor may not be correlated with recurrence either. There is also a possibility that contrast agent may drain faster in a tumor with a higher MVD and that this change manifests as lower attenuation in the nephrographic phase. However, there was no significant difference in average $\mathrm{TA}_{\text {cor }}-\mathrm{TA}_{\text {neph }}$ between groups with and without recurrence $(47.3 \mathrm{HU} v s .51 .9 \mathrm{HU}$, calculated from Table II).

Regions showing massive necrosis or hemorrhage were avoided when placing ROIs on each tumor in the present study, but the presence of minute and scattered necrosis in a tumor can contribute to low tumor enhancement in the nephrographic phase, as the spatial resolution of CT would limit its detection. Tumor necrosis is defined as microscopic coagulative necrosis characterized by homogeneous clusters and sheets of degenerating and dead cells (9). Veeratterapillay et al. suggested that necrosis might have contributed to their findings of lower maximum contrast enhancement on dynamic CT even though they specifically avoided cystic change, necrosis and calcification when placing their ROIs on tumors (14). Again, the presence of

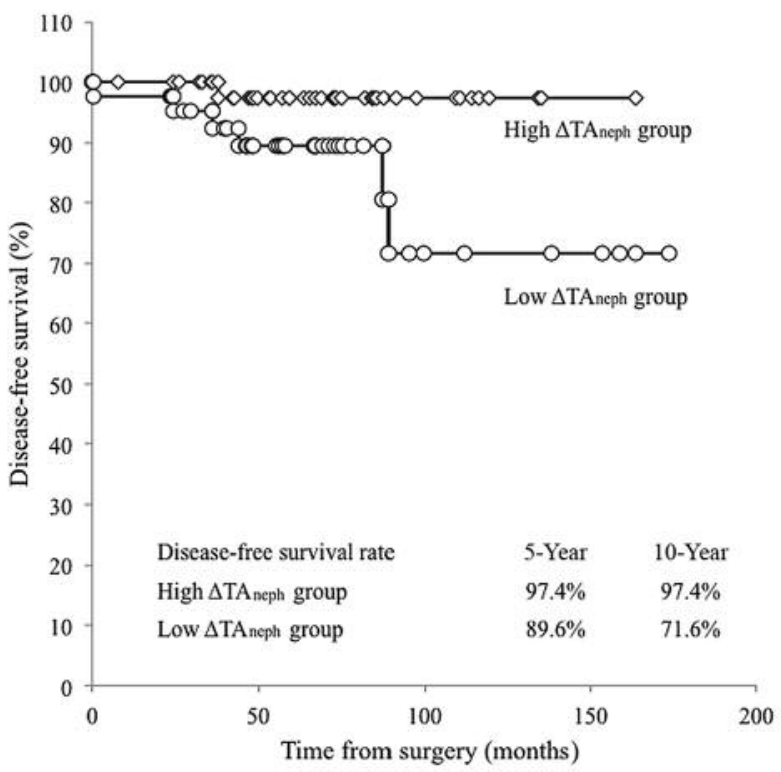

Figure 1. Disease-free survival curves of patients with clear cell renal cell carcinoma (ccRCC) according to $T A_{\text {neph }}-T A_{\text {pre }}\left(\Delta T A_{\text {neph }}\right)$. The median value of $\triangle T A_{\text {neph }}$ in 88 ccRCCs was $86 \mathrm{HU}$. Based on this value, ccRCCs were divided into two groups: high $\triangle T A_{\text {neph }}$ group $(\geq 86$ $H U)$ and low $\triangle T A_{\text {neph }}$ group $(<86 \mathrm{HU})$. The disease-free survival rate of the high $\triangle T A_{\text {neph }}$ group was significantly higher than that of the low $\Delta T A_{\text {neph }}$ group $(p<0.05) . T A_{\text {pre }}, T A_{\text {neph }}$ : Pre-contrast and nephrographic phase tumor attenuation, respectively.

histological tumor necrosis is reported to represent an independent predictor with respect to metastasis-free and overall survival in patients with clear cell and papillary RCC (9). These reports support our hypothesis regarding the prognostic significance of tumor enhancement in the nephrographic phase. Although minute and scattered necrosis in a tumor may be correlated with worse tumor grade (21), the Fuhrman grade itself was not a predictive factor in the present study. We consider that $\Delta \mathrm{TA}_{\text {neph }}$ may reflect minute and scattered necrosis in a tumor rather than tumor vascularity and fibrous stroma. Veeratterapillay et al. (14) proposed maximum contrast enhancement in the corticomedullary phase as a prognostic factor of ccRCC. Because our patient population and analysis approach were different from theirs, it is difficult to state which parameter is more useful in this regard.

Tumor size has been reported to be a prognostic factor for ccRCC (22). Tumor size and age at diagnosis were reported as prognostic factors at $\mathrm{T} 1$ stage (23-25). The present study, however, showed no significant correlation between tumor size and recurrence after surgery although tumor size tended to be correlated with disease-free survival. Our findings suggest that tumor enhancement in the nephrographic phase is of greater value than tumor size for prediction of 

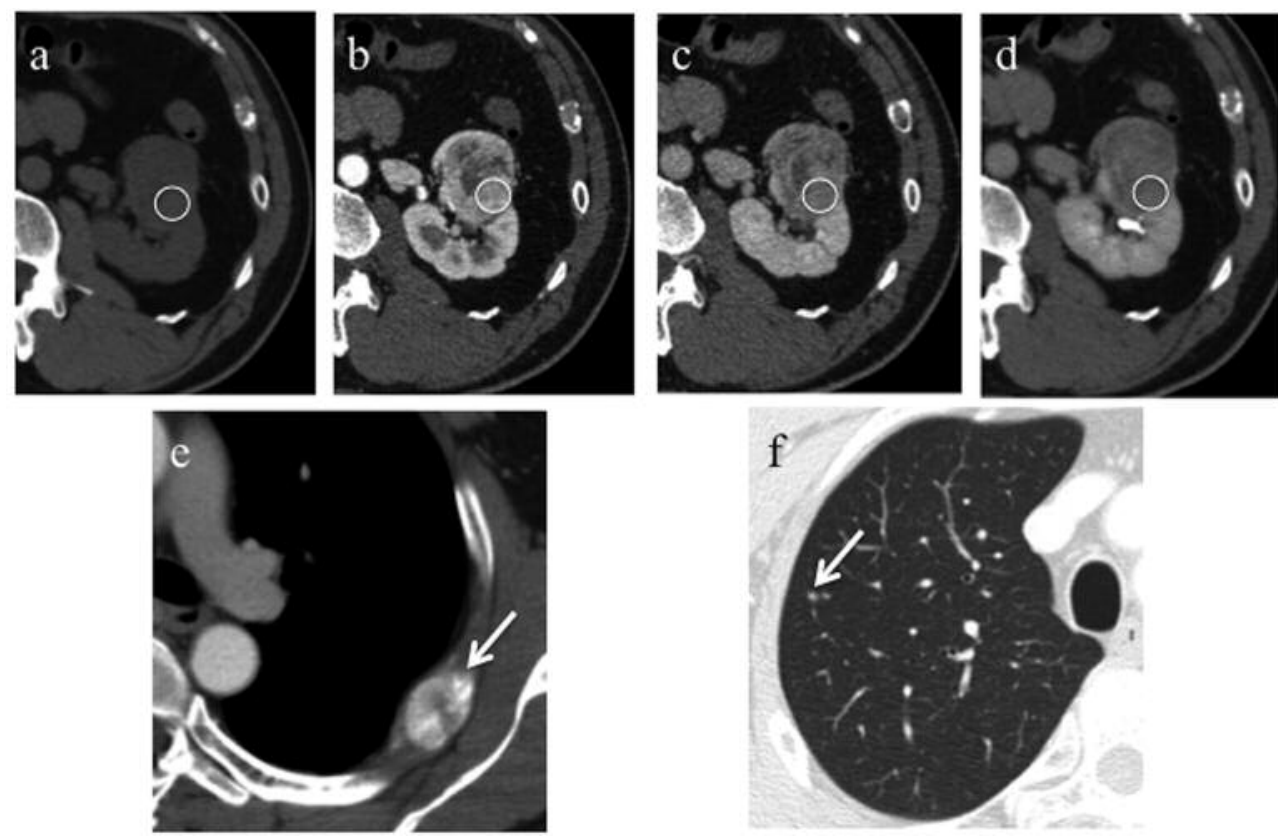

Figure 2. Pre-contrast (a), corticomedullary phase (b), nephrographic phase (c), excretory phase $(d)$, and postoperative (e and f) chest computed tomography $(C T)$ for a 58-year-old female with 3.8-cm clear cell renal cell carcinoma showing low $T A_{\text {neph }}-T A_{\text {pre }}\left(\Delta T A_{\text {neph }}\right)$. Preoperative dynamic CT revealed a heterogeneously enhanced mass in the left kidney $(a-d)$. On each image, a region of interest was placed to cover as much of the solid region of the mass as possible, while avoiding hemorrhage, degeneration and necrosis. The $T A_{\text {pre }}, T A_{c o r}, T A_{n e p h}$ and $T A_{\text {ex }}$ values were 47.7, 181.6, 120.5 and $100.9 \mathrm{HU}$, respectively. $\triangle T A_{\text {neph }}$ was $72.8 \mathrm{HU}$. Chest CT 44.1 months after surgery showed lung (e) and bone (f) metastases (arrows). $T A_{\text {pre }}, T A_{\text {cor }}, T A_{n e p h}, T A_{e x}$ : Pre-contrast, corticomedullary, nephrographic and excretory phase tumor attenuation, respectively.
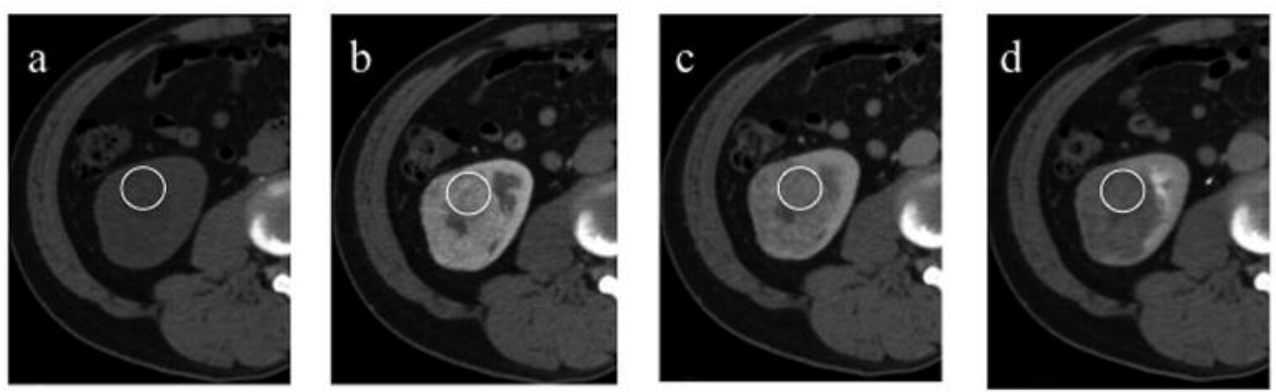

Figure 3. Pre-contrast (a), corticomedullary phase (b), nephrographic phase (c), excretory phase (d) for a 35-year-old male with 5.4-cm clear cell renal cell carcinoma showing high $T A_{n e p h}-T A_{\text {pre }}\left(\Delta T A_{n e p h}\right)$. Preoperative dynamic $C T$ revealed a heterogeneously enhanced mass in the right kidney. On each image, a region of interest was placed to cover as much of the solid region of the mass as possible, while avoiding hemorrhage, degeneration and necrosis. The $T A_{\text {pre }}, T A_{c o r}, T A_{n e p h}$ and $T A_{e x}$ values were $21.2,150.3,110.4$ and $76.3 \mathrm{HU}$, respectively. $\triangle T A_{\text {neph }}$ was $89.2 \mathrm{HU}$. This case showed no recurrence 69.0 months after surgery. $T A_{\text {pre }}, T A_{c o r}, T A_{n e p h}, T A_{e x}$ : Pre-contrast, corticomedullary, nephrographic and excretory phase tumor attenuation, respectively.

recurrence. This parameter can also be measured and calculated with ease. For data analysis, we used average values of the five radiological parameters measured independently by the two radiologists. Inter-reader agreement of $\Delta \mathrm{TA}_{\text {neph }}$ was excellent. This parameter has high reproducibility and is suitable for practical use.
There are a few limitations to the present study. Firstly, two CT protocols were used for evaluation. This is a problem that occurred due to renewal of CT equipment at our Institution because we collected patients who underwent nephrectomy between January 2001 and May 2013. The scan timing of the corticomedullary phase slightly differed 
between the protocols, although the difference was only $3 \mathrm{~s}$. However, since the scan timing of the nephrographic phase was identical, it was assumed there would be no influence on $\Delta \mathrm{TA}_{\text {neph}}$. Secondly, the amount and injection speed of contrast agent were constant. A different result for $\mathrm{TA}_{\text {cor }}-$ $\mathrm{TA}_{\text {pre }}$ can be obtained if they are adjusted based on the body weight of a patient. Thirdly, only a small number of patients $(8.0 \%)$ showed recurrence after surgery in the present study. This is probably due to our patients our inclusion of patients with pT1 stage ccRCC only. The volume of contrast agent used in daily practice may be insufficient for evaluating tumor enhancement or the vascularity of a large tumor even if the same scan timing is used. To exclude this potentially cofounding factor, we decided to focus only on small tumors. Muramaki et al. reported that postoperative disease recurrence developed in $5.2 \%$ of localized pT1 RCCs (25). The recurrence rate in our study was higher than that. Another reason for this could be that many patients followed-up after surgery at other hospitals were excluded. This might have resulted in selection bias. However, since we enrolled patients from 2001, a long-term follow-up that seemed to be sufficient for analysis of prognosis was obtained for each patient. Fourthly, the number of ccRCCs of Fuhrman grade 3 or more and venous invasion was small. This may also be due to our including patients with pT1 stage ccRCC only. Although the number of patients ( 88 cases) in our study was relatively large, different results might be obtained with a larger patient cohort.

In conclusion, tumor enhancement in the nephrographic phase was found to be a predictive factor for recurrence after nephrectomy in patients with localized stage T1 ccRCC. The application of dynamic CT before surgery may be useful, not only for the diagnosis of a renal tumor, but also to predict its recurrence after surgery.

\section{Conflicts of Interest}

The Authors declare that they have no conflict of interest in regard to this study. No grant or fund supported this work.

\section{Acknowledgements}

The Authors thank Professor Yoshinao Oda, Department of Anatomic Pathology, Kyushu University, for providing the pathological information and Professor Masatoshi Eto, Department of Urology, Kyushu University, for providing the clinical information.

\section{References}

1 Motzer RJ, Bander NH and Nanus DM: Renal cell carcinoma. N Engl J Med 335: 865-875, 1996.

2 Eble JN, Sauter G and Epstein JI: World Health Organization. Classification of tumours. Pathology and genetics of tumours of the urinary system and male genital organs. Lyon, IARC Press, 2004.
3 Kim JK, Kim TK, Ahn HJ, Kim CS, Kim KR and Cho KS: Differentiation of subtypes of renal cell carcinoma on helical CT scans. Am J Roentgenol 178: 1499-1506, 2002.

4 Jinzaki M, Tanimoto A, Mukai M, Ikeda E, Kobayashi S, Yuasa Y, Narimatsu Y and Murai M: Double-phase helical CT of small renal parenchymal neoplasms: correlation with pathologic findings and tumor angiogenesis. J Comput Assist Tomogr 24: 835-842, 2000.

5 Sauk SC, Hsu MS, Margolis DJA, Lu DS, Rao NP, Belldegrun AS, Pantuck AJ and Raman SS: Clear cell renal cell carcinoma: multiphasic multidetector CT imaging features help predict genetic karyotypes. Radiology 261: 854-862, 2011.

6 Saroufim A, Messai Y, Hasmim M, Rioux N, Lacovelli R, Verhoest G, Bensalah K, Patard JJ, Albiges L, Azzarone B, Escudier B and Chouaib S: Tumoral CD105 is a novel independent prognostic marker for prognosis in clear-cell renal cell carcinoma. Br J Cancer 110: 1778-1784, 2014.

7 Delahunt B, Bethwaite PB and Thornton A: Prognostic significance of microscopic vascularity for clear cell renal cell carcinoma. Br J Urol 80: 401-404, 1997.

8 Qi L, Du J, Zhang Z, Diao L, Chen X and Yao X: Low differentiated microvascular density and low expression of platelet-derived growth factor-BB (PDGF-BB) predict distant metastasis and poor prognosis in clear cell renal cell carcinoma. BJU Int 112: E415-423, 2013.

9 Pichler M, Hutterer GC, Chromecki TF, Jesche J, KampelKettner K Rehak P, Pummer K and Zigeuner R: Histologic tumor necrosis is an independent prognostic indicator for clear cell and papillary renal cell carcinoma. Am J Clin Pathol 137: 283-289, 2012.

10 Iakovlev VV, Gabril M, Dubinski W, Scorilas A, Youssef YM, Faragalla H, Kovacs K, Rotondo F, Metias S, Arsanious A, Plotkin A, Girgis AH, Streutker CJ and Yousef GM: Microvascular density as an independent predictor of clinical outcome in renal cell carcinoma: an automated image analysis study. Lab Invest 92: 46-56, 2012.

11 Ha YS, Park YH, Kang SH, Hong SH, Hwang TK, Byun SS and Kim YJ: Predictive factors for late recurrence in patients with stage T1 clear cell renal cell carcinoma: a multiinstitutional study. Clin Genitourin Cancer 11: 51-55, 2013.

12 Delahunt B, Kittelson JM and McCredie MRE: Prognostic importance of tumor size for localized conventional (clear cell) renal cell carcinoma. Cancer 94: 658-664, 2002.

13 Lau WK, Cheville JC, Blute ML, Weaver AL and Zinche H: Prognostic features of pathologic stage T1 renal cell carcinoma after radical nephrectomy. Urology 59: 532-537, 2002.

14 Veeratterapillay R, Ijabla R, Conaway D, Haslam P, Soomro N and Heer R: Contrast-enhanced CT in 100 clear cell renal cell cancers: an analysis of enhancement, tumour size, and survival. Clinical Radiology 70: 1357-1361, 2015.

15 Nishie A, Kakihara D, Asayama Y, Ishigami K, Ushijima Y, Takayama Y, Okamoto D, Fujita N, Morita K, Kubo Y, Inokuchi $\mathrm{J}$ and Honda H: Apparent diffusion coefficient: An associative factor for recurrence after nephrectomy in localized renal cell carcinoma. J Magn Reson Imaging 43: 166-172, 2016.

16 Nisman B, Appelbaum L, Yutkin V, Nechushtan H, Hubert A, Uziely B, Pode D and Peretz T: Serum thymidine kinase 1 activity following nephrectomy for renal cell carcinoma and radiofrequency ablation of metastases to lung and liver. Anticancer Res 36: 1791-1797, 2016. 
17 Kadono Y, Kawaguchi S, Nohara T, Shigehara K, Narimoto K, Izumi K, Ikeda H, Yaegashi H, Miyagi T, Nakashima T, Seto C and Mizokami A: Evaluation of factors affecting metastasis for renal cell carcinoma based on current guidelines in Japan. Anticancer Res 37: 5147-5153, 2017.

18 Bier S, Aufderklamm S, Todenhöfer T, Kruck S, Schuster K, Rausch S, Othman A, Notohamiprodjo M, Nikolaou K, Schwentner C, Stenzl A, Bier G and Bedke J: Prediction of postoperative risks in laparoscopic partial nephrectomy using RENAL, Mayo Adhesive Probability and renal pelvic score. Anticancer Res 37: 1369-1373, 2017.

19 Yoshimitsu K, Irie H, Tajima T, Nishie A, Asayama Y, Hirakawa M, Nakayama T, Kakihara D and Honda H: MR imaging of renal cell carcinoma: its role in determining cell type. Radiat Med 22: 371-376, 2014.

20 Nishie A, Asayama Y, Ishigami K, Kakihara D, Nakayama T, Ushijima Y, Takayama Y, Yokomizo A, Tatsugami K, Inokuchi J, Fujita N, Kubo Y, Aishima S, Hirakawa M and Honda H: Pathological manifestation of difference in washout pattern of adrenal hyperplasia on dynamic CT. J Med Imaging Radiat Oncol 58: 559-564, 2014.

21 Chen J, Sun J, Xing W, Ding J, Chen T, Dai Y, Sun J and Hu J: Prediction of nuclear grade of clear cell renal cell carcinoma with MRI: intratumoral susceptibility signal intensity versus necrosis. Acta Radiol 55: 378-384, 2014.
22 Zigeuner R, Hutterer G, Chromecki T, Imamovic A, KampelKettner K Rehak P, Langner C and Pummer K: External validation of the Mayo Clinic stage, size, grade, and necrosis (SSIGN) score for clear-cell renal cell carcinoma in a single European centre applying routine pathology. Eur Urol 57: 102$109,2010$.

23 Jorns J, Thiel DD, Lohse C, Lohse CM, Williams A, Arnold ML, Cheville JC, Leibovich BC and Parker AS: Three-dimensional tumour volume and cancer-specific survival for patients undergoing nephrectomy to treat pT1 clear-cell renal cell carcinoma. BJU Int 110: 956-960, 2012.

24 Sakai I, Miyake H, Muramaki M, Kondo Y, Kusuda Y, Yamada $\mathrm{Y}$ and Fujisawa M: Significant impact of age at diagnosis on the prognosis of Japanese patients with pT1 renal cell carcinoma following surgical resection. BJU Int 109: 695-699, 2011.

25 Muramaki M, Miyake H, Sakai I, Kondo Y, Kusuda Y, Yamada $\mathrm{Y}$ and Fujisawa M: Age at diagnosis as a powerful predictor for disease recurrence after radical nephrectomy in Japanese patients with pT1 renal cell carcinoma. Int J Urol 11: 121-125, 2011.

Received January 12, 2018

Revised February 12, 2018

Accepted February 13, 2018 